\title{
Quantitative trait locus analysis for ear height in maize based on a recombinant inbred line population
}

\author{
Z.Q. Li ${ }^{4,5}$, H.M. Zhang ${ }^{1,4}$, X.P. Wu ${ }^{1,4}$, Y. Sun ${ }^{3,4}$ and X.H. Liu' \\ ${ }^{1}$ Maize Research Institute, Shanxi Academy of Agricultural Sciences, \\ Xinzhou City, China \\ ${ }^{2}$ College of Life Sciences, China West Normal University, \\ Nanchong City, China \\ ${ }^{3}$ Biotechnology Research Center, Shanxi Academy of Agricultural Sciences, \\ Taiyuan City, Shanxi, China \\ ${ }^{4}$ Key Laboratory of Crop Gene Resources and Germplasm Enhancement on \\ Loess Plateau, Ministry of Agriculture, China \\ ${ }^{5}$ Millet Research Institute, Shanxi Academy of Agricultural Sciences, \\ Changzhi City, China \\ Corresponding author: X.H. Liu \\ E-mail: liuxiaohong0817@aliyun.com
}

Genet. Mol. Res. 13 (1): 450-456 (2014)

Received August 18, 2013

Accepted October 20, 2013

Published January 21, 2014

DOI http://dx.doi.org/10.4238/2014.January.21.13

\begin{abstract}
Maize (Zea mays L.) is among the crops with the greatest worldwide economic importance. Ear height is a very important trait that is considered necessary in maize and is related to morphology, lodging, and yield. To realize its genetic basis, an $\mathrm{F}_{9}$ recombinant inbred line population and a genetic map consisting of 101 simple sequence repeat markers were used to detect the quantitative trait locus (QTL) for ear height, and the result showed that one QTL on chromosome 1 was identified with a mapping interval of $5 \mathrm{cM}$ to its linked marker Umc1358. The QTL from elite inbred line Mo17 could explain $9.55 \%$ of the phenotypic variance, and because of the additive effect, it could result in an ear height increase of $4.86 \mathrm{~cm}$.
\end{abstract}


This result was beneficial for understanding the genetic basis of ear height in maize.

Key words: Maize (Zea mays L.); Ear height; Quantitative trait locus; Recombinant inbred line

\section{INTRODUCTION}

Maize (Zea mays L.) is among the crops with the greatest worldwide economic importance. It has been used as human and animal food, as well as raw material in the high-technology industry. In terms of breeding, it is one of the most studied species and has been used as a model in many situations (Sabadin et al., 2008). Among the various traits that are normally considered in breeding programs, plant morphology is one of the most important traits; thus, improving the plant morphology is regarded as a significant goal for improving maize yield (Wang et al., 2008).

Ear height is a trait that is considered necessary in the maize breeding project. It is related to morphology, lodging, and yield; therefore, understanding its genetic basis has important theoretical and practical meaning. Quantitative trait locus (QTL) mapping is a wellreasoned solution to realize the genetic basis of traits in crop breeding. Currently, there are many studies on the QTL that affect agronomic traits in maize, such as yield (Coque and Gallais, 2006; Ribaut et al., 2007), florescence (Szalma et al., 2007; Liu et al., 2010), and plant morphology (Ku et al., 2010). With respect to the ear height trait, some QTL were also identified from published reports (Kraja and Dudley, 2000; Flint-Garcia et al., 2003; Lima et al., 2006; Yang et al., 2008). Nevertheless, different studies provided different results, including QTL number, distribution, and genetic effect. This could probably be explained by many differences, including parental materials, segregation-population types, ecological conditions, and genetic maps. For example, Lima et al. (2006) used maize inbred lines L-20-01F and L02-03D as parental lines, and 9 QTL for ear height were located on chromosomes 2 (two), 3 (two), 4 (one), 7 (one), 9 (two), and 10 (one). In the report by Sibov et al. (2003), L-08-05F and L-14-4B were employed as parents, and 5 QTL were identified on chromosomes 1 (one), 7 (three), and 9 (one). Additionally, previous segregation populations that were used to detect the QTL for maize ear height were mainly based on temporal $\mathrm{F}_{2}$ (Wu et al., 2005; Zhang et al., 2006a), while a recombinant inbred line (RIL) population that possessed the trait of immortality was hardly applied.

Therefore, an RIL population derived from Mo17 x Huangzao4 was used to map the QTL associated with maize ear height in our study. The objectives of this study were to understand more clearly the genetic basis of ear height and look for the molecular marker that can be used in marker-assisted selection breeding in maize.

\section{MATERIAL AND METHODS}

\section{Plant materials}

The plant materials in this study included maize inbred lines Mo17 and Huangzao4 and an $\mathrm{F}_{9}$ RIL population consisting of 239 RILs. Mo17 and Huangzao4 are the representa- 
tive lines of Lancaster and Tangsipingtou heterotic groups, respectively. The RIL population was derived from the cross between the 2 parental lines, Mo17 and Huangzao4.

\section{Field experiments and statistical analyses}

All of the 241 lines were sown in a completely randomized design with 6 replicates at the experiment field (Shanxi Academy of Agricultural Sciences, Xinzhou City, Shanxi Province, China) that had single-row planting for each replicate, 20 plants per row, 66.7$\mathrm{cm}$ row intervals, and $25-\mathrm{cm}$ plant intervals within a row. During florescence, the middle 10 plants of every replicate of each line were individually investigated for ear height. In total, 60 plants per line were used to compute the mean. Based on the 239 means of the RIL population, the SPSS11.5 software (www.spss.com) was used to perform descriptive statistics.

\section{QTL mapping}

Based on the means of each line of the population and the genetic map consisting of 101 simple sequence repeat markers and covering $1422.7 \mathrm{cM}$ of the genome (Zhang et al., 2006b), the QTL that were associated with ear height were identified by composite interval mapping (CIM) with the Windows QTL Cartographer 2.5 software (Wang et al., 2010 ) using $2.0 \mathrm{cM}$ as the walk speed and a $\log _{10}$ of odds ratio (LOD) of 2.5 as the QTL significance threshold as described in previous reports (Qi et al., 1998; Gilliland et al., 2006). Control parameters included the standard CIM model, 5 control markers, $10 \mathrm{cM}$ as the window size, and the forward regression method. The QTL with an LOD value that was greater than the threshold value will be presented, and their position and genetic effects and percentage of phenotypic variation were estimated at the significant LOD peak in the region. Then, the identified QTL were mapped with the Mapchart 2.1 software (Voorrips, 2002).

\section{RESULTS}

\section{Phenotypic observations and statistical analysis}

The ear height results showed that the tested lines presented variations. Of the parental lines, the ear height of Mo17 was up to $85.9 \mathrm{~cm}$, which was much higher than that of Huangzao4 $(69.2 \mathrm{~cm})$. The descriptive statistics for the RIL population are displayed in Table 1. The frequency distribution graph of the ear height in the RIL population (Figure 1) was consistent with a normal distribution, which suggested that ear height was a quantitative trait and was controlled by multiple genes.

Table 1. Descriptive statistics of the recombinant inbred line population for the trait ear height.
\begin{tabular}{|lccccccc}
\hline Maximum $(\mathrm{cm})$ & Minimum $\mathrm{cm})$ & Range $(\mathrm{cm})$ & Mean $(\mathrm{cm})$ & SD & CV $(\%)$ & Skewness & Kurtosis \\
\hline 125.3 & 39.5 & 85.8 & 71.2 & 15.171 & 21.299 & 0.526 & 0.559 \\
\hline $\mathrm{SD}=$ standard deviation; $\mathrm{CV}=$ coefficient of variation.
\end{tabular}




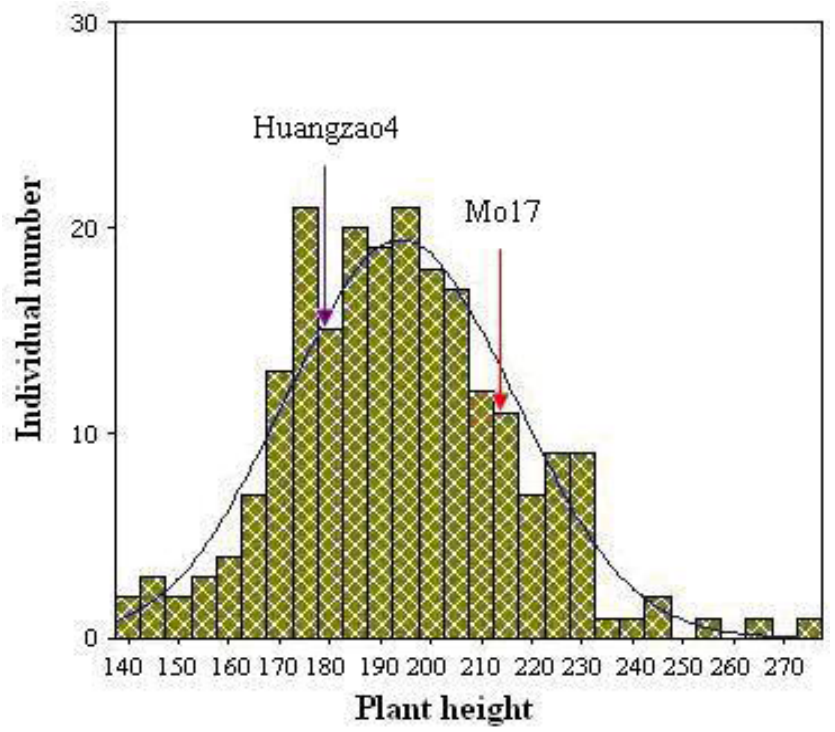

Figure 1. Frequency distribution graph of the recombinant inbred line population for the trait ear height in maize.

\section{QTL identification}

The Mapping software was used to detect the QTL for ear height. As a result, 1 QTL was detected on chromosome 1 (Qeh) (Figure 2) and was flanked by Umc1358 and Phi308707. The QTL could explain $9.55 \%$ of the phenotypic variance (Table 2). Because of the additive effect, the QTL could increase ear height by $4.86 \mathrm{~cm}$. According to the phenotypic values of the parental lines and the additive effect value of the QTL, we concluded that the QTL that was identified in this study was from Mo17.

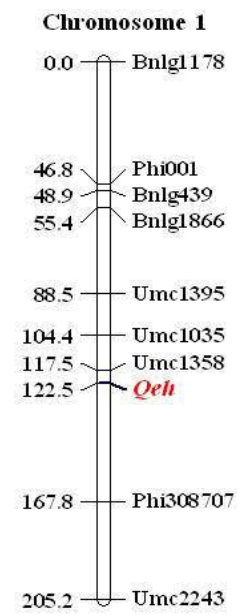

Figure 2. Chromosomal position of the quantitative trait loci (QTL) for ear height identified using a recombinant inbred line population derived from Mo17 x Huangzao4. One QTL named Qeh was mapped on chromosome 1, flanked by Umc1358 and Phi308707. 
Table 2. Quantitative trait loci (QTL) for ear height identified using a recombinant inbred line population derived from Mo17 x Huangzao4.

\begin{tabular}{lcccccc}
\hline Loci & Chr. & Adjacent markers & anterval (cM) & LOD & $R^{2}(\%)$ & Additive effect \\
\hline Qeh & 1 & Umc1358 & 5.0 & 2.77 & 9.55 & 4.86 \\
\hline
\end{tabular}

The mapping distance between QTL and its adjacent markers; LOD $=\log _{10}$ of odds ratio; $R^{2}=$ percentage of phenotypic variance explained by QTL.

\section{DISCUSSION}

Maize ear height is one of the most important agronomic traits. To realize clearly its genetic basis, an $\mathrm{F}_{9}$ RIL population consisting of 239 lines that were derived from the cross Mo17 x Huangzao4 was used to detect the QTL for ear height. Our results demonstrated that 1 QTL named Mo17 was mapped on chromosome 1 and was flanked by Umc1358 and Phi308707.

There have been many studies that aimed to identify QTL for ear height in maize (Zhang et al., 2006a; Yang et al., 2008; Bai et al., 2010), and some QTL were located on different chromosomes of maize. Compared to previous studies, our results were different in terms of QTL number, location, and genetic effects. This probably was caused by differences in the studies, including mapping parents, segregation populations, ecological conditions, and genetic maps.

To be noted, the parental lines in our study were also those that were used to map the QTL for ear height by Lan and Chu (2005), but we obtained different results, and the main differences were listed in Table 3. Although both of the QTL on chromosome 1 presented positive affective effects, the two parents provided opposite phenotypic values in the 2 experiments. Mo17 had a lower value for ear height than that of Huangzao4 in Lan and Chu (2005), while in our study, the phenotypic value of Mo17 was higher that than of Huangzao4. Furthermore, the values of phenotypic variation that were explained by the QTL and the additive effect in our study were much higher than those in their study. Consequently, the two QTL identified by different experiments were different.

\begin{tabular}{|c|c|c|c|c|}
\hline References & Population type & Ecological regions & Marker types $^{a}$ & QTL [Chr. No. (QTL number)] \\
\hline $\begin{array}{l}\text { Lan and Chu (2005) } \\
\text { This study }\end{array}$ & $\begin{array}{l}F_{2} \\
\text { RIL }\end{array}$ & $\begin{array}{l}\text { Beijing, China } \\
\text { Xinzhou, China }\end{array}$ & $\begin{array}{l}\text { SSR and AFLP } \\
\text { SSR }\end{array}$ & $\begin{array}{l}1 \text { (one), } 5 \text { (one), } 6 \text { (two), } 8 \text { (one), } 10 \text { (one) } \\
1 \text { (one) }\end{array}$ \\
\hline
\end{tabular}

${ }^{\mathrm{a}} \mathrm{SSR}=$ simple sequence repeat; AFLP $=$ amplified fragment length polymorphism

The QTL that was identified in our study was far away from its adjacent marker, Umc1358, which had a mapping interval of $5 \mathrm{cM}$. This suggested that the linked marker would not co-segregate with the gene controlling ear height within the QTL, so it cannot directly be used for marker-assisted selection in breeding project. No QTL were detected on other chromosomal regions; the cause of this was probably the too small genetic effects of other loci or wide marker interval for partial regions on the genetic map. Therefore, to map the locus finely and find more loci that are associated with ear height, other molecular markers must be added 
to the corresponding chromosomal regions. This study is in progress and is based on the immortal RIL population and established genetic map.

In summary, an RIL population that was derived from the cross between Mo17 and Huangzao4 was used to detect the QTL for ear height. Our results showed that 1 QTL mapped to chromosome 1 and had a mapping interval of $5 \mathrm{cM}$ with its linked marker Umc1358. The QTL from Mo17 could explain 9.55\% of the phenotypic variance, and because of the additive effect, it could increase ear height by $4.86 \mathrm{~cm}$. This result was beneficial for understanding the genetic basis of ear height in maize.

\section{ACKNOWLEDGMENTS}

Research supported by the Major Project for Genetically Modified Organisms Breeding from China Agriculture Ministry, P.R. China (\#2011ZX08003-001) and the Project for the Doctoral Research Program from Shanxi Academy of Agricultural Sciences, P.R. China (\#YBSJJ1106).

\section{REFERENCES}

Bai W, Zhang H, Zhang Z, Teng F, et al. (2010). The evidence for non-additive effect as the main genetic component of plant height and ear height in maize using introgression line populations. Plant Breed. 129: 376-384.

Coque M and Gallais A (2006). Genomic regions involved in response to grain yield selection at high and low nitrogen fertilization in maize. Theor. Appl. Genet. 112: 1205-1220.

Flint-Garcia SA, McMullen MD and Darrah LL (2003). Genetic relationship of stalk strength and ear height in maize. Crop Sci. 43: 23-31.

Gilliland LU, Magallanes-Lundback M, Hemming C, Supplee A, et al. (2006). Genetic basis for natural variation in seed vitamin E levels in Arabidopsis thaliana. Proc. Natl. Acad. Sci. U. S. A. 103: 18834-18841.

Kraja AT and Dudley JW (2000). QTL analysis of two maize inbred line crosses. Maydica 45: 1-12.

$\mathrm{Ku}$ LX, Zhao WM, Zhang J, Wu LC, et al. (2010). Quantitative trait loci mapping of leaf angle and leaf orientation value in maize (Zea mays L.). Theor. Appl. Genet. 121: 951-959.

Lan JH and Chu D (2005). Study on the genetic basis of plant height and ear height in maize (Zea mays L.) by QTL dissection. Yi. Chuan 27: 925-934.

Lima MDA, de Souza CL, Bento DAV, de Souza AP, et al. (2006). Mapping QTL for grain yield and plant traits in a tropical maize population. Mol. Breed. 17: 227-239.

Liu XH, Zheng ZP, Tan ZB, Li Z, et al. (2010). QTL mapping for controlling anthesis-silking interval based on RIL population in maize. Afr. J. Biotechnol. 9: 950-955.

Qi X, Niks RE, Stam P and Lindhout P (1998). Identification of QTLs for partial resistance to leaf rust (Puccinia hordei) in barley. Theor. Appl. Genet. 96: 1205-1215.

Ribaut JM, Fracheboud Y, Monneveux P, Banziger M, et al. (2007). Quantitative trait loci for yield and correlated traits under high and low soil nitrogen conditions in tropical maize. Mol. Breed. 20: 15-29.

Sabadin PK, Souza CL Jr, Souza AP and Garcia AAF (2008). QTL mapping for yield components in a tropical maize population using microsatellite markers. Hereditas 145: 194-203.

Sibov ST, de Souza CLJ, Garcia AA, Silva AR, et al. (2003). Molecular mapping in tropical maize (Zea mays L.) using microsatellite markers. 2. Quantitative trait loci (QTL) for grain yield, plant height, ear height and grain moisture. Hereditas 139: 107-115.

Szalma SJ, Hostert BM, Ledeaux JR, Stuber CW, et al. (2007). QTL mapping with near-isogenic lines in maize. Theor. Appl. Genet. 114: 1211-1228.

Voorrips RE (2002). MapChart: software for the graphical presentation of linkage maps and QTLs. J. Hered. 93: 77-78.

Wang S, Basten CJ and Zeng ZB (2010). Windows QTL Cartographer 2.5. Department of Statistics, North Carolina State University, Raleigh. Available at [http://statgen.ncsu.edu/qtlcart/WQTLCart.htm]. Accessed March 10, 2010.

Wang YD, Duan MX, Xing JF, Zhao JR, et al. (2008). Progress and prospect in ideal plant type breeding in maize. $J$. Maize Sci. 16: 47-50. 
Wu JW, Liu C, Shi YS, Song YC, et al. (2005). QTL analysis of plant height and ear height in maize under different water regimes. J. Plant Genet. Resour. 6: 266-271.

Yang XJ, Lu M, Zhang SH, Zhou F, et al. (2008). QTL mapping of plant height and ear position in maize (Zea mays L.). Yi. Chuan 30: 1477-1486.

Zhang HW, Liu YJ, Guo XL, Zhang F, et al. (2006a). QTL mapping for callus induction and plant regeneration in maize immature embryos. Acta Agronom. Sin. 32: 385-389.

Zhang ZM, Zhao MJ, Ding HP, Rong TZ, et al. (2006b). Quantitative trait loci analysis of plant height and ear height in maize (Zea mays L.). Rus. J. Genet. 42: 306-310. 